\title{
Fully Flexible, Polymer-based Microwave Devices Part I: Materials, Fabrication Technique, and Application to Transmission Lines
}

\author{
Iurii Cherukhin, Si-Ping Gao, Member, IEEE, Yong Xin Guo, Member, IEEE
}

\begin{abstract}
To achieve fully flexible microwave devices, we investigated flexible polymers in terms of chemical, mechanical, and electrical properties. Moreover, the fabrication techniques for polymer-based microwave devices have been developed to address chemical adhesion and demolding issues. Finally, based on formulated criteria, we have developed recipes for low-loss (0.001), low-Dk (1.73) flexible dielectric materials and applied them to the microstrip and CPW transmission lines. The microstrip and CPW lines' transmission loss is as low as 0.065 and $0.034 \mathrm{~dB} / \mathrm{cm}$ at $2.5 \mathrm{GHz}$, respectively. The effects of various materials on microwave performance have been analyzed, from which we show acceptable limits for fully flexible microwave devices in $S$ and $L$ bands. The proposed molding process allows us to step out from 2D PCB designs and build 3D structures or hybrid PCB-3D components with a certain freedom in material properties. Additionally, the new material exhibits unique mechanical properties, which extends the material application to other fields. This work demonstrates that polymer-based flexible microwave electronics can have a competitive performance compared to rigid PCB technology. Additionally, it has been found that the polymer-based devices have significant performance improvements at elevated temperatures, which can be exploited in a high-temperature application.
\end{abstract}

Index Terms - PDMS, flexible, microstrip, CPW, polymerbased, conductive polymer, low-loss material.

\section{INTRODUCTION}

$\mathrm{F}$ LEXIBLE microwave electronics is an emerging technology and has all chances to stand along with the common commercial technology such as PCB and metal waveguides. The demand for flexible electronics is not limited by wearable applications [1], [2]. Mechanical flexibility allows withstanding significant deformations without the destruction of the devices. This feature can be exploited under extreme operational conditions like rapid acceleration, immense

Manuscript received December 7, 2020; revised XXX; This work was supported in part by XXX.

I. Cherukhin is with the Department of Electrical and Computer Engineering, National University of Singapore, 4 Engineering Drive 3, 117583, Singapore (e-mail: $\quad \underline{\text { urii.cherukhin@u.nus.edu; }}$ Iurii.Cherukhin@gmail.com).

S. P. Gao is with the Department of Electrical and Computer Engineering, National University of Singapore, 4 Engineering Drive 3, 117583, Singapore (e-mail: gaosp@nus.edu.sg).

Y. X. Guo is with the Department of Electrical and Computer Engineering, National University of Singapore, 4 Engineering Drive 3, 117583, Singapore (e-mail: yongxin.guo@nus.edu.sg). vibrations, various deformations, including twisting, bending, and stretching.

The flexible microwave electrons can be roughly divided into three groups by types of conducting and dielectric materials: 1) semi-ridged [3], [4], [5], which are based on very thin Roger, Duroid, or LCP (liquid crystal polymer) substrates with copper cladding; 2) thin-flexible [6], [7], [8], which are based on PEN (polyethylene naphthalate), PET (polyethylene terephthalate) and Kapton (polyimide) and similar rigid polymers with copper cladding or 3D printed Ag-inks; 3) polymer-based [9], [10], which are produced fully or partially from elastomers and can have substrate thickness more than 1 $\mathrm{mm}$ without significant impacts on the flexibility.

Fully flexible polymer-based microwave devices are promising and can be integrated into hybrid-PCB or fairly complex 3D structures with variations in mechanical and electrical properties. Such an approach provides additional freedom for designs, greatly extends the possible areas of applications and working conditions. Poly-based microwave devices can benefit from polymer's features, e.g., self-healing capabilities [11], [12], electro-mechanical actuation [13], [14], etc., which brings the new approach for reconfigurability of microwave devices.

The microwave devices' requirements are quite strict, i.e., surface roughness, dimension tolerances, electrical properties of materials, additional requirements for flexibility, and many others. We will demonstrate in this work that some requirements could be mitigated or varied in order to achieve the optimum balance between microwave performance and mechanical flexibility by implementing suitable production technology and material engineering. The first approach to answer this question has been demonstrated in our previous works [15], [16].

\section{MATERIALS AND CHARACTERIZATION}

\section{A. Dielectric Elastomers and Discussion.}

Using the coaxial and waveguide transmission line methods, we have analyzed the microwave properties of a series of elastomers in order to find out the suitable candidate and possible correlations among chemical compositions, the dielectric loss, and the dielectric constant (Dk). The analyzed polymers include DI-7540 and DI-7542 from ECM company, 
SBS (styrene-butadiene-styrene) and SEBS (Styrene-ethylenebutylene-styrene) co-polymers, TangoPlus FLX930, PDMS (polydimethylsiloxane) Sylgard 184, Sylgard 170, MS1002, SE 1740, EG3896, SE 7450 from Dow Chemical, natural latex from Casting Craft and Knorr Prandell, butyl rubber with different molecular weight Kalene 800 (isobutylene-isoprene co-polymer) and Isolene 40 (polyisoprene) from HBfuller and few others commercially available elastomers. From the analyzed polymers (Fig. 1, Fig. 2), we have come to the conclusion that low loss polymers must have the minimum dipole moment in the polymer molecule, i.e., the amount of double bonds, phenyl rings, combinations of unshielded strong-weak bonds like fluorocarbon or fluorosilicone must be minimized. Following these criteria, it is highly likely to meet low loss properties for elastomers even without characterization.

Although this must be treated with caution, the cases when fluorine is distributed around polymer molecules can create the minimum dipole moment due to the shielding effect (more positive or negative atoms are locked inside the structure). An excellent example of such an effect is PTFE (Polytetrafluoroethylene). From these guides, we can assume that linear polymers with only carbon in the backbone structure should have a very low dielectric loss. Indeed, polyethylene (LDPE/HDPE) has a dielectric loss of around 0.0003 at $3 \mathrm{Ghz}$. In contrast, TangoPlus FLX930 has a variety of oxygen-carbon and nitrate-carbon bonds, double bonds, and phenyl ring structures in all monomers and shows 0.06 dielectric loss (Fig. 2), Dk around 3.05 (Fig. 1) at 3GHz. On the other hand, SBS shows a dielectric loss of 0.0015 and Dk of 2.3, even though the chemical structure has phenyl rings in styrene and double bonds in butadiene. The SBS polymer molecule is more linear than FLX930 and has a certain ratio between styrene and butadiene, which reduces the amount of phenyl rings; hence, the dipole moment is relatively small, which leads to small dielectric loss. However, SBS and SEBS are thermoplastics and can be used in flexible electronics only when the material's layer is relatively thin (100um range) but serves as an example of chemical criteria in this work.

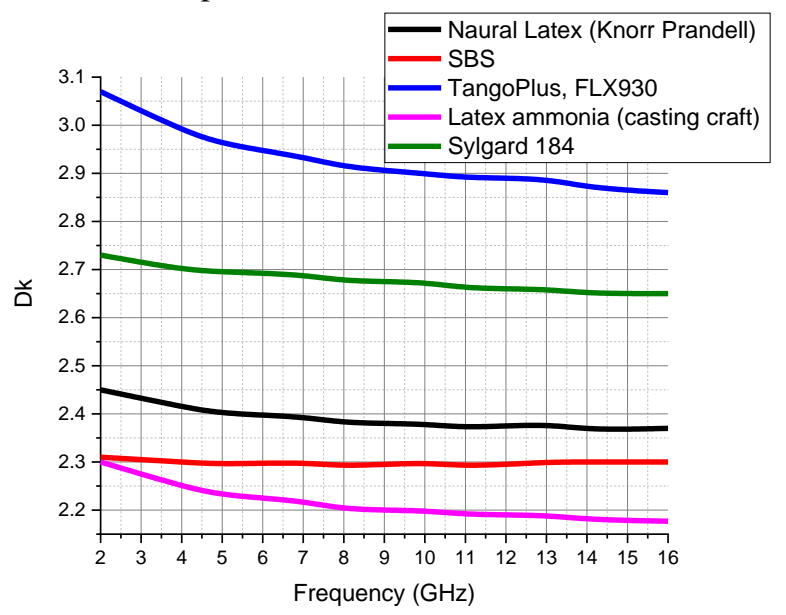

Fig. 1. The dielectric constants of a few analyzed polymers. The coaxial transmission line method has been used for these measurements.

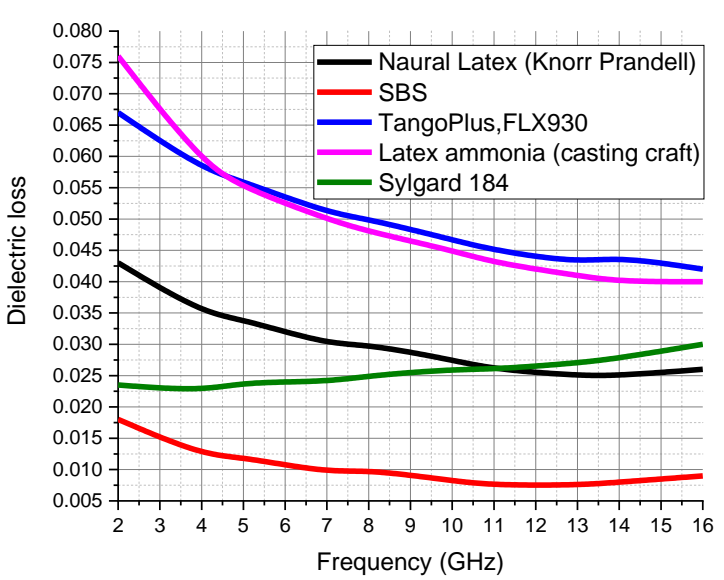

Fig. 2. The dielectric loss of a few analyzed polymers. The coaxial transmission line method has been used for these measurements.

PDMS (Sylgard 184, Sylgard 170, SE 1740, EG3896, MS1002, SE 7450) has a Si-oxygen backbone surrounded by methyl groups and cross-links [17]. Sylgard 170 has similar mechanical properties to Sylgard 184, although it has carbon black filling in it, which slightly increases the Dk from 2.8 (in Sylgard 184, MS1002) to 3.1. The molecular weight (the length of the polymer's molecule) and the amount of crosslinks directly influence the mechanical properties. Therefore, we modify the mechanical properties by varying the content of single-ended vinyl-terminated monomers (cross-links) in the pre-polymerized PDMS. Such structural changes also influence the microwave properties.

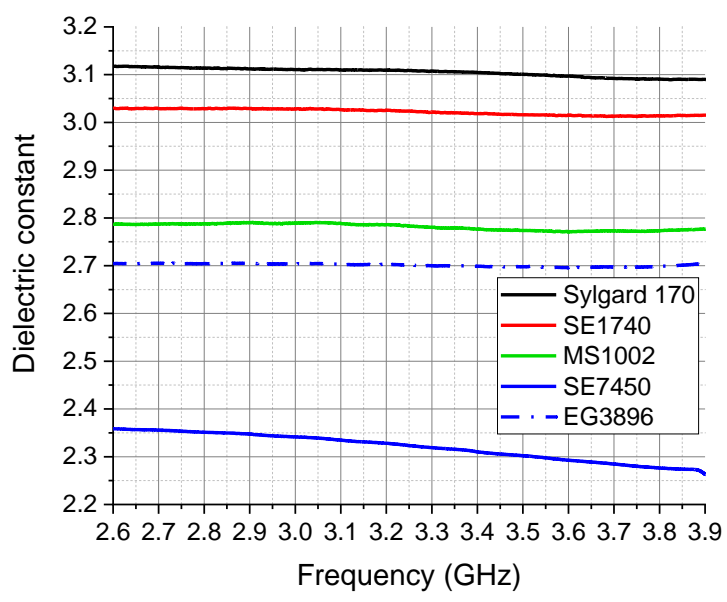

Fig. 3. The dielectric constants of PDMS grades. The waveguide transmission line method has been used for these measurements (S-band). 


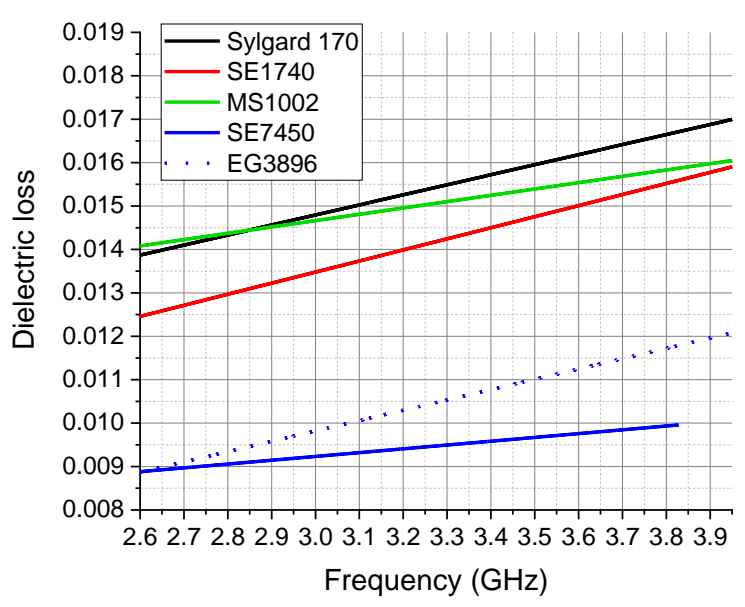

Fig. 4. The dielectric loss of PDMS grades. The waveguide transmission line method has been used for these measurements (S-band).

In general, PDMS is versatile and easily scalable in production, biocompatible, inert to various solvents [18], and allows for tuning desired properties with minimum effort.

The most popular way to tune dielectric constant and dielectric loss is to mix with ceramics, e.g. $\mathrm{Al}_{2} \mathrm{O}_{3}$ [19], $\mathrm{SiO}_{2}$ [20], $\mathrm{SrTiO}_{3}$ [21], $\mathrm{TiO}_{2}$ [22], [23], $\mathrm{BaTiO}_{3}$ [24], $\mathrm{BaZnTaO}_{3}$ [25], and many others [26], [27], [28], [29], [30]. This method reduces the dielectric loss to a certain extent, but the increase in the $\mathrm{Dk}$ is inevitable, which might be beneficial for miniaturization but might be less desirable for the antenna's performance. There are several drawbacks. Firstly, the ceramic volumetric proportion of composites is limited to $40 \% \mathrm{v} / \mathrm{v}$ [28], because of the viscosity of pre-polymerized PDMS (as a matrix) and the size of ceramic powder, which sets a certain limit for "solubility". The matrix can not hold ceramic granules any longer; hence, compounding and molding are not possible. We have observed that Sylgard 170 (less viscous than Sylgard 184) and 45um powder of $\mathrm{Al}_{2} \mathrm{O}_{3}$ has the maximum volumetric ratio around $20-25 \%$, and $45 \mathrm{um}$ $\mathrm{SrTiO}_{3}$ has $10-15 \%$. Secondly, the high ceramic filling ratios will lead to excessive humidity absorption and mechanical rigidity to the point when flexibility comparable to rigid PCB.

On the contrary, flexible fillings with a suitable flexible matrix can avoid the above compounding limitations and enhance microwave properties. As for the flexible matrix, we have found out that PDMS gel EG3896 from Dow Chemical generally has a less dielectric loss and very low viscosity (which increases the "solubility" of fillings) at the compounding and molding stages, in addition to its superior flexibility of polymerized material. This PDMS gel is also useful to tune the mechanical properties of other PDMS grades like Sylgard 170 and Sylgard184, e.g., Sylgard 184 has Young's modulus $100 \mathrm{MPa}$ and Sylgard $184+50 \% \mathrm{w} / \mathrm{w}$ EG3896 has 0.6 MPa.

As for the filling, the compounding of microspheres with suitable elastomers can provide outstanding electrical and mechanical properties. There are several types of microspheres: $\mathrm{SiO}_{2}$ based when shells are made of glass and have a wall thickness less than a micron, such as the product of $3 \mathrm{M}$ company or microspheres with polymer shells as Nouryon Expancel DET and DUT series. Both types of microspheres have grades depends on the particle size.

To further enhance the compound's electrical and mechanical properties, co-polymers 7558 and 7680, capable of promoting chemical adhesion and uniform distribution of microspheres within PDMS during polymerization, are used. Both co-polymers are dissolved in a small amount of toluene (can be replaced by xylene or a combination of both). Toluene provides the flowability of co-polymers for compounding and wettability of microsphere's surfaces, making the compound more homogeneous.

The compound includes EG-3896 PDMS gel, DET or 3M microspheres, co-polymer 7558, or 7680 from DOW Chemical. Such a combination is able to lift the microspheres volumetric ratio to at least $60 \% \mathrm{v} / \mathrm{v}$ (with granular size 3555 um).

The mixture can be degassed in a vacuum chamber in order to remove trapped air bubbles. Microspheres 3M K20, iM16k, Nouryon DET 40, and DUT 40 have been tested in the vacuum $0.09 \mathrm{MPa}$ and showed no damage to the shells. Polymerization can be done at elevated temperatures from 50 degrees Celsius and higher till a fully polymerized state. The temperature accelerated polymerization prevents phase separation between microspheres and dimethylsiloxane since the microspheres' density is less than PDMS. Fig. 5 shows the distribution of the microspheres in the compound Sylgard 170 and $3 \mathrm{M} \mathrm{K20}$. It illustrates the homogeneous distribution of microspheres in the matrix, where the size of the microsphere's diameters ranges from $25 \mathrm{um}$ to $95 \mathrm{um}$.

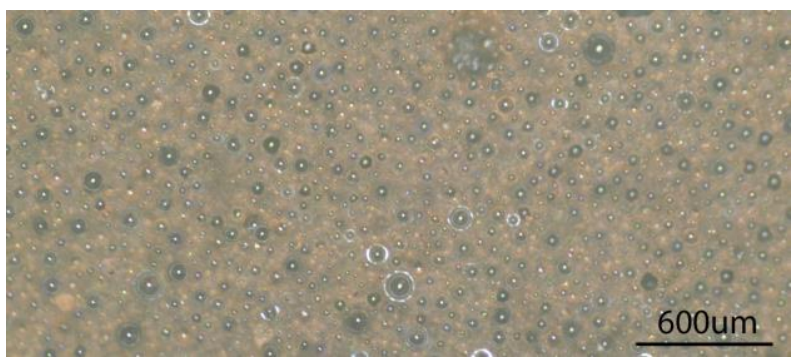

Fig. 5. 3M K20 microspheres distribution in PDMS Sylgard 170 (vol 50\%).

The combination of EG-3896 and microspheres alone can provide excellent properties, which suits well for microwave electronics. Fig. 6 shows the comparison of Sylgard 170 with the compound of EG-3896 with vol. 50\% K20 microspheres (modified PDMS). A summary of a few selected PDMS, PDMS-microspheres, and PDMS-ceramic composites is shown in TABLE I [24] (Vf is a volumetric fraction), which shows the compound's superior electrical properties. The dielectric loss becomes 0.0034 at $2.6 \mathrm{GHz}$, and it is already comparable to commercial, rigid $\mathrm{PCB}$ substrates like $\mathrm{RO} 4003 \mathrm{C}$ or RO4350B, which have dielectric loss 0.0027 and 0.0037 accordingly. We also notice that the substitution of $50 \%$ volume of PDMS by microspheres gives a three-time reduction in dielectric loss with an expected reduction in Dk. 
Since "solubility" of low viscosity PDMS (EG-3896) can hold up to $60 \% \mathrm{v} / \mathrm{v}$ fillings, we can achieve the minimum dielectric loss with a wide range of $\mathrm{Dk}$ (from 1.8 to 15) by using a combination of ceramics, like $\mathrm{SrTiO}_{3}$ and microspheres with various ratios. Further, it will require modification of existing mixing theoretical models, i.e., Lichtenecker, Landau-Lifshitz, Maxwell-Garnett, etc., for three and more compound structures.

The further improvements have been archived with a recipe EG3896 + vol. 50\% DET $40+3 \% 7558$ co-polymer. Such combination gives no variations of dielectric constant over frequency in the wideband from $2.6 \mathrm{GHz}-12.5 \mathrm{GHz}$ and very small dielectric loss, i.e., $\mathrm{Dk}$ is equal to 1.73 and dielectric loss is $0.001 \pm 0.0005$ at $2.6 \mathrm{GHz}$ to $3.95 \mathrm{GHz}$ and $0.01-0.014$ at $8.4 \mathrm{GHz}$ to $12.5 \mathrm{GHz}$, and the material samples have been cured at 100C.

Additionally, we have investigated the impact of the curing temperature and the component's proportion (black/white) on the mechanical and microwave properties. Sylgard 170 has been taken as an example. Several batches with different component's proportions (white/black: 50/50, 35/65, 65/35) have been cured at $100 \mathrm{C}, 25 \mathrm{C}$, and $-2 \mathrm{C}$ ( 2 months of curing) and measured Young's modulus, Dk, and dielectric loss at $\mathrm{S}$ and $\mathrm{X}$ band (TABLE II). Lower curing temperature leads to lower dielectric loss; the component's proportion has a direct influence on Young's modulus. However, in this research, samples, and devices have been cured at $100 \mathrm{C}$ and 50/50 component's ratio (if it is not stated otherwise) to achieve a fast production cycle, which is the worst-case scenario.

TABLE I

PDMS, PDMS-CERAMIC COMPOSITES

\begin{tabular}{|c|c|c|c|c|}
\hline Name & $\begin{array}{l}\text { Vf of } \\
\text { filler }\end{array}$ & $\begin{array}{c}\text { Frequency } \\
\mathrm{GHz} \\
\end{array}$ & Dk & $\begin{array}{c}\text { Dielectric } \\
\text { loss } \\
\end{array}$ \\
\hline Sylgard 170 & 0 & 2.6 & 3.1 & 0.014 \\
\hline EG3896 & 0 & 2.6 & 2.7 & 0.009 \\
\hline PDMS- $\mathrm{Al}_{2} \mathrm{O}_{3}$ & 0.46 & 5 & 5.8 & 0.0095 \\
\hline PDMS-AIN & 0.4 & 5 & 4.8 & 0.0172 \\
\hline $\mathrm{PDMS}_{-\mathrm{BaZnTaO}}$ & 0.3 & 5 & 6.6 & 0.0098 \\
\hline $\mathrm{PDMS}_{-\mathrm{BaTiO}_{3}}$ & 0.27 & 5 & 13.4 & 0.0435 \\
\hline $\mathrm{PDMS}_{-} \mathrm{SrTiO}_{3}$ & 0.3 & 5 & 14.2 & 0.0116 \\
\hline $\begin{array}{l}\text { PDMS- } \\
\mathrm{Li}_{2} \mathrm{ZnTi}_{3} \mathrm{O}_{8}\end{array}$ & 0.36 & 5 & 7.5 & 0.0098 \\
\hline $\mathrm{PDMS}_{-\mathrm{CaNdTiO}}$ & 0.43 & 5 & 11.9 & 0.0115 \\
\hline $\begin{array}{l}\text { EG3896- } \\
\text { microspheres }\end{array}$ & 0.5 & 2.6 & 1.9 & 0.0034 \\
\hline
\end{tabular}

TABLE II

SYLGARD 170 WITH DIFFERENT CONDITIONS

\begin{tabular}{cccccc}
\hline \hline Condition & $\begin{array}{c}\text { Young's } \\
\text { modulus (MPa) }\end{array}$ & \multicolumn{2}{c}{ Dk } & \multicolumn{2}{c}{ Dielectric loss } \\
\hline Frequency (GHz) & & 2.6 & 10 & 2.6 & 10 \\
50/50 100C & 1.1 & 3.1 & 3.07 & 0.014 & 0.022 \\
$50 / 5025 \mathrm{C}$ & 1.04 & 3.05 & 3.08 & 0.012 & 0.021 \\
$50 / 50-2 \mathrm{C}$ & - & 3.21 & 2.23 & 0.009 & 0.018 \\
35/65 100C & 1.5 & 3.04 & 3.08 & 0.015 & 0.023 \\
35/65 25C & 1.42 & 3.07 & 3.12 & 0.014 & 0.021 \\
65/35 100C & 0.9 & 3 & 3.02 & 0.012 & 0.021 \\
65/35 25C & 0.84 & 3 & 3.05 & 0.01 & 0.021 \\
\hline \hline
\end{tabular}

Another critical parameter is moisture absorption since water content in the material leads to excessive dielectric loss, changes in Dk [31], mechanical degradations, and partial or full loss of flexibility at $\mathrm{OC}$ and below. The moisture absorption measurements have been done by soaking samples in the pure, deionized water for 24 hours with weight measurements of the samples before and after soaking. The results are summarized in TABLE III with comparison to ceramic-based compounds [30]. Having moisture absorption at $0.067 \%$ means that EG3896-DET 40 with 50\%v/v can be used as a low-loss material for various electronics applications because moisture absorption below $0.1 \%$ is a requirement for packaging [32].

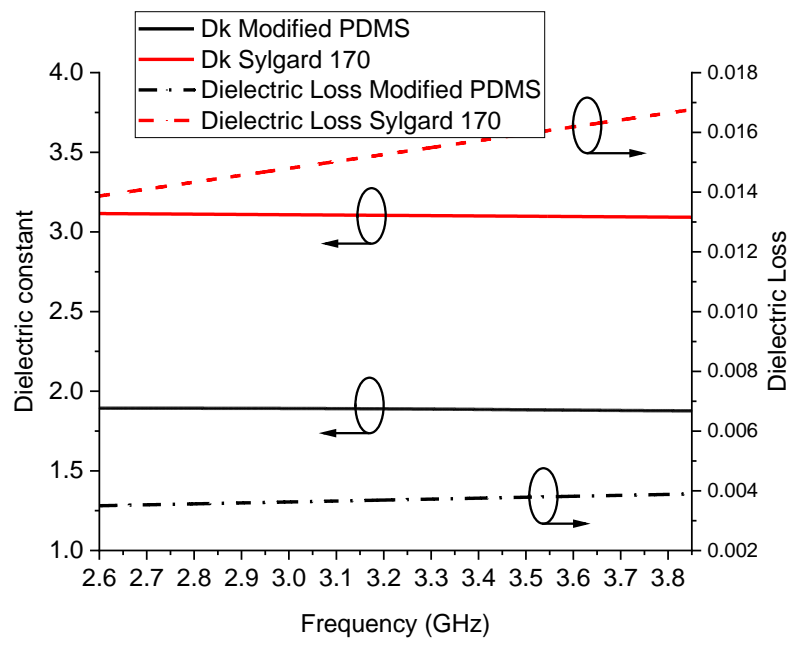

Fig. 6. Measured dielectric constants and dielectric loss of modified PDMS and Sylgard 170. The waveguide transmission line method has been used for these measurements.

TABLE III

PDMS, PDMS-CERAMIC COMPOSITES MOISTURE ABSORPTION

\begin{tabular}{ccc}
\hline \hline Name & $\begin{array}{c}\text { Density } \\
(\mathrm{g} / \mathrm{cc})\end{array}$ & $\begin{array}{c}\text { Moisture absorption } \\
(\text { vol.\%) }\end{array}$ \\
\hline Sylgard 170 & 1.35 & 0.031 \\
Sylgard 184 & 1.03 & 0.047 \\
EG3896 & 0.94 & 0.002 \\
$\mathrm{SE1740}$ & 1.02 & 0.019 \\
PDMS-Al $\mathrm{O}_{3}$ & -- & 0.347 \\
PDMS-AlN & -- & 0.108 \\
PDMS-BaZnTaO $_{3}$ & -- & 0.115 \\
PDMS-BaTiO $_{3}$ & -- & 0.116 \\
PDMS-SrTiO $_{3}$ & -- & 0.089 \\
PDMS-SiO $_{2}$ & -- & 0.1 \\
EG3386-DET40 50\% $_{\text {EG3896-K20 50\% }}$ & 0.526 & 0.067 \\
\hline \hline
\end{tabular}

The mechanical properties of the dielectric polymer have been analyzed and improved. TABLE IV summarizes a small part of the gathered data and indicates how the microspheres' size and type influence the final compound's mechanical properties. Smaller microspheres size gives less stiff compounds. DET microspheres with plastic shells are better than glass-based microspheres. Additionally, we have observed the damping of mechanical vibration and acoustic waves in the EG3896-DET compound.

TABLE IV

MEASURED YOUNG'S MOdULUS OF DIELECTRIC POLYMERS. CURED AT 100C.

\begin{tabular}{cc}
\hline \hline Name & Young's modulus (MPa) \\
\hline Sylgard 184 & 100 \\
Sylgard 170 & 1.1 \\
SE 1740 & 0.1 \\
Sylgard 170+K20 50\% & 7.36 \\
Sylgard 170+im16 50\% & 7.97 \\
Sylgard 170+DET40 50\% & 2.9 \\
EG3896+K20 50\% & 0.14 \\
EG3896+im16 50\% & 0.066 \\
EG3896+DET40 50\% & 0.06 \\
\hline \hline
\end{tabular}


In summary, PDMS molecule is far from optimum, and further improvements can be made by using low molecular weight butyl rubber (Kalene 800 and Isolene 40). These polymer grades have relatively low viscosity. Previously high molecular weight butyl rubber with ceramic fillings like $\mathrm{TiO}_{2}$ or $\mathrm{BaSrTiO}_{3}$ has been investigated [33], [34] where the dielectric losses are around 0.0027 and 0.009 at $5 \mathrm{GHz}$, respectively [30]. However, pure butyl rubber has Dk around 2.35 and dielectric loss 0.0009 at $3 \mathrm{GHz}$. Using the LandauLifshitz model, we can predict that Dk can be reduced to 1.6 with microspheres. Based on our previous experiments with microspheres, we predict that the dielectric loss could be reduced by $50-75 \%$ (i.e., $0.00045-0.00023$ ) with $50 \%$ fillings.

\section{B. Conducting polymers}

Another critical component in polymer-based microwave electronics is a conducting polymer with the ability to stretch above 1 or $2 \%$. The conducting polymers from EMS (CI series), DuPont (PE873), and Dow Chemical (DA6534) companies have been purchased and tested. The "uncured" state of such polymers consists of $60 \%$ silver nanoparticles in some based polymer with solvents (CI series) or PDMS based without solvent (DA6534). CI series conducting polymers have slightly different conductivity, viscosity, surface roughness, stretching, and bending abilities. TABLE V summarizes conductivity from the datasheet and measurements. The measurements have been done by the 4point probe technique.

The conducting polymers can be tuned to the required properties. The conductivity can be increased by rising metal filling proportion either in the bulk material [35] or at the interface between the substrate and conducting layer by additional passivation with metal particles [36]. By investigating various methods, we have found experimentally that the most straightforward and suitable approach (in terms of implementation and integration in our production process) in enhancing conductivity is to add a very small amount of conducting particles with a very large aspect ratio (length to diameter ratio) [36]. Copper nanotubes and copper nanowires with large aspect ratio would be the best solution in such case, but they are still not available commercially. We used copper bonding wires with $50 \mathrm{um}$ in diameter and 10 to $30 \mathrm{~mm}$ in length. The length has been chosen arbitrarily based on the required device's dimensions and stretchability. Such short wires could be evenly distributed either in the volume of "uncured" polymers or on the surface. The conductivity of CI1036 has been increased 4 times by implementing this way (see CI-1036 mod in TABLE V).

TABLE V

POLYMER CONDUCTIVITY

\begin{tabular}{ccc}
\hline \hline Name & $\begin{array}{c}\text { Datasheet Conductivity } \\
\left(10^{6} \mathrm{~S} / \mathrm{m}\right)\end{array}$ & $\begin{array}{c}\text { Measured Conductivity } \\
\left(10^{6} \mathrm{~S} / \mathrm{m}\right)\end{array}$ \\
\hline CI-1036 & 3.9 & 1.6 \\
CI-1036 mod & & 6.75 \\
CI-1075 & 3.6 & 4.2 \\
CI-4040 & 0.78 & 0.7 \\
DA6534 & 0.55 & 0.45 \\
\hline \hline
\end{tabular}

The mechanical properties of the CI series are very different. CI-4040 is quite flexible, but conductivity is low. This grade might be used from the shelf in flexible electronics. CI-1075 is rather brittle, especially with $70-100 \mu \mathrm{m}$ thickness (50um is 5 skin depths), and application in flexible electronics is not the best choice without additional modifications. CI1036 is in the middle and suitable for property engineering. DuPont PE873 has the best stretchability with relatively high conductivity $\left(1 * 10^{6} \mathrm{~S} / \mathrm{m}\right)$. Dow DA6534 is PDMS based, and chemical adhesion happens naturally with PDMS dielectric substrates. This grade has very good mechanical properties.

The general approach to modify stretchability is in rising elastomer proportion in the mix. There is a trade-off between electrical and mechanical properties. We have used Dow copolymers $9250,9176,7558,7680$, and others with various terminations and molecular weights. Stretchability has been improved in all cases at the expense of conductivity. Technically, it would be possible to mitigate conductivity drop by using inherently conductive polymers like polyaniline or similar. TABLE VI illustrates changes in conductivity versus Young's modulus. The effect of the elastomer's molecular weight (7680 has low and 9176 has high molecular weight) is different. The 7680 helps to reduce Young's modulus three times with a reduction in conductivity by the same proportion after a certain threshold (14\%), while the 9176 co-polymer drastically reduces conductivity by three orders of magnitude. We can also observe that a small amount of the co-polymers makes the final polymer stiffer with ambiguous changes in conductivity. The excessive stiffness can be explained by forming additional cross-linking in the matrix with copolymers, which enforces the structure. Since the molecular weight of the co-polymers is different, and therefore the effect on the stiffness is different. The conducting polymers are the stiffest part of the polymer-based devices, and they require additional research effort to find a suitable balance between mechanical and electrical properties.

$$
\text { TABLE VI }
$$

PROPERTIES OF CONDUCTING POLYMERS

\begin{tabular}{ccc}
\hline \hline Name & $\begin{array}{c}\text { Young's modulus, } \\
\text { MPa }\end{array}$ & $\begin{array}{c}\text { Measured Conductivity } \\
(\mathrm{S} / \mathrm{m})\end{array}$ \\
\hline CI-1036 & 310 & $1.6 \times 10^{6}$ \\
CI-1036+8\% 7680 & 460 & $1.66 \times 10^{6}$ \\
CI-1036+14\% 7680 & 100 & $0.7 \times 10^{6}$ \\
CI-1036+8\% 9176 & 980 & $0.47 \times 10^{6}$ \\
CI-1036+18\% 9176 & 95 & $3.14 \times 10^{3}$ \\
CI-1036+7\% 7558 & 725 & $2.8 \times 10^{6}$ \\
CI-1036+17\% 7558 & 130 & $0.19 \times 10^{6}$ \\
CI-4040 & 150 & $0.7 \times 10^{6}$ \\
DA6534 & 210 & $0.45 \times 10^{6}$ \\
\hline \hline
\end{tabular}

\section{Summary}

In this work, we use Sylgard 170 and EG-3896 - 50\%v/v K20 microspheres compound with variations of different conducting polymers CI-1036, CI-1036 mod, CI-1075, CI404, DA6534 to investigate the effects of dielectric loss, conductivity, and mechanical impact on the microwave performance of transmission lines. 


\section{FABRICATION TECHNIQUE}

In this section, based on molding technology, we have developed our production process, which is versatile with regard to all our polymers, curing conditions, chemical integration, etc. Fig. 7 shows the mold for the bow-tie antenna and CPW line. All parts are made from PTFE. PTFE is chemically inert and reduces the chances of having a chemical adhesion of polymers.

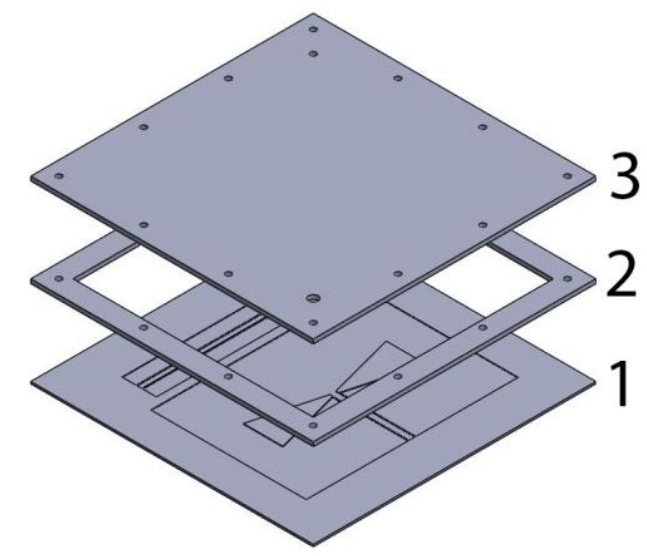

Fig. 7. The mold for the bow-tie antenna and CPW line.

Part 1 in Fig. 7 is a mask for the conducting layer. The conducting polymer in the pre-polymerized condition is in the liquid state and must be contained in a certain volume during polymerization and further integrations. The volume can be machined by a milling machine or $\mathrm{CNC}$. The dimension variation and surface roughness of the final microwave device are directly influenced by the machining quality. By using the Roland milling machine, our final production tolerances are 10um in XY-plane and 50-80um in Z-plane, which is sufficient for our cases.

Even though PTFE is inert and should not have chemical adhesion to conducting polymers, the machined surfaces of PTFE are relatively rough. It leads to very high surface energy, which makes almost impossible the demolding process for CI series polymers. To resolve that issue, we have covered volumes for conducting polymer with a non-stick coating SYL-OFF SB-7558 and SYL-OFF 4000 catalyst [37]. The non-stick coating is based on PDMS and can help demold all polymers except PDMS based conducting polymers. However, the SYL-OFF SB-7558 can not adhere to PTFE.

To provide strong chemical adhesion SYL-OFF SB-7558 with PTFE, we used the following technique. The machined surfaces of the mold are cleaned by the standard procedure with acetone, isopropyl alcohol, and deionized water sequentially. Then the mold must be treated in a vacuum chamber with argon RF plasma $150 \mathrm{~W}$ with $20 \mathrm{sccm}\left(\mathrm{cm}^{3} / \mathrm{min}\right)$ flow for 5 minutes and then purged with oxygen with $20 \mathrm{sccm}$ for the same time. This treatment allows to remove of fluorine atoms from exposed PTFE chains and attach oxygen to carbon atoms. Then the surface is wetted with Dowsil $1200 \mathrm{OS}$ and followed with drying for 20 minutes at $50-60{ }^{\circ} \mathrm{C}$ in the oven. And the final step is applying the mixture of SYL-OFF SB7558 and SYL-OFF 4000 catalyst on the surface and curing at
$100-120{ }^{\circ} \mathrm{C}$ in the oven. This procedure helps to bind the nonstick coating to PTFE with a very long-lasting effect. The surface exposed by argon plasma can be easily bonded with PDMS or other polymers. Therefore, surfaces not to be coated must be masked. We have used a stationary glue stick, which can be easily washed out with water after all treatments.

Part 2 in Fig. 7 is a spacer between part 1 and part 3, and its height depends on the required device's substrate thicknesses. Part 3 is a lid with injection holes for the dielectric polymers. This part can also be realized as part 1 with machined volumes for the conducting polymers in the case of a ground plane.

All conducting polymers are filled in the required volumes and cured following the recommendations from the datasheets. To reduce bubbles appearing in the bulk material and improve surface quality, we cured polymer at relatively low temperatures, e.g., $60-70{ }^{\circ} \mathrm{C}$ for $40-60 \mathrm{~min}$ (must be adjusted based on the layer thickness) then increased to $100-120{ }^{\circ} \mathrm{C}$ till the full cured state. The mold can be assembled after the conducting layers are ready. Degassed dielectric polymers were injected with syringes via injection holes, and then the whole assembly can be either placed in the oven or cured at room temperature.

The conducting polymers CI series are not polymerizing but rather drying. $30 \%-40 \%$ of the "pre-polymerized" polymer is a solvent. This means that the "post-polymerized" layer shrinks. CI-4040 polymer shrinks from 50\% to 65\%. CI-1036, 1075 have $72 \%-80 \%$ shrinkage. DA6534 has no shrinkage (real polymerization). Considering the shrinkage and requirements for skin depth, the machined volume for the conducting polymer must have 350um in depth to obtain 70-100um thickness of the final conducting layer. 50um is 5 skin depths at $2.5 \mathrm{GHz}$ with conductivity $1 * 10^{6} \mathrm{~S} / \mathrm{m}$.

Since the PDMS has low adhesion to other polymers, it is crucial to provide chemical bonding with conducting polymers. We developed the following solution. First, the cured conducting polymers' surface must be wetted with Dowsil $12000 \mathrm{O}$ and dried at room temperature prior to $5 \mathrm{~min}$ drying at $100{ }^{\circ} \mathrm{C}$. The small amount of dielectric PDMS is mixed with Dow 7558 co-polymer at 2\%-3\% by weight. Second, this mixture is applied on the cooled surfaces of conducting polymers with a relatively thin layer and cured for some time. Because the 7558 co-polymer has four types of terminations, including vinyl type, it gives chemical adhesion to PDMS and other polymers. Additionally, 7558 co-polymer is dissolved in a very small amount of toluene, increasing the wetting effect, slightly dissolves conducting polymer, and forming chemical bonds. Last, more dielectric PDMS layer is applied. PDMS to PDMS adhesion happens naturally during polymerization. For the same reason, DA6534 does not require additional treatments to bind with PDMS. 


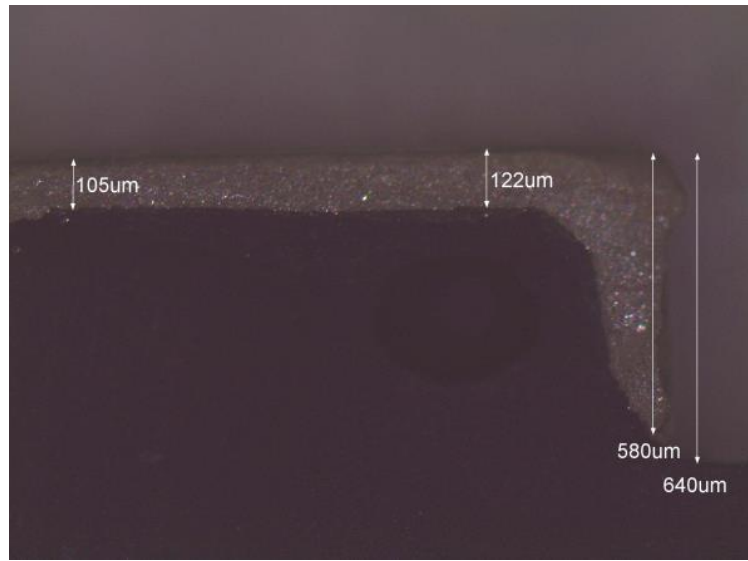

Fig. 8. The cross-section of the edge of the produced microstrip line from Sylgard 170 and PE873.

The cross-sections of produced conducting layers have $\pi$ shaped, as illustrated in Fig. 8. This shape increases coupling effects to the nearest lines. By varying the initial volumes and shapes for conducting and dielectric layers, we can produce not only planar structures but complex, full 3D geometries. This opens up another degree of freedom for engineering filters, antennas, and many other microwave devices.

Following the described production technology, we have produced several sets of CPW lines and microstrip lines, as shown in Fig. 9. The antenna's performance and bending effects will be discussed in part II of this work [38].

$$
\text { TABLE VII }
$$

PRODUCED MICROSTRIP AND CPW LINES

\begin{tabular}{lcccc}
\hline \hline & \multicolumn{2}{c}{ CPW lines } & \multicolumn{2}{c}{ Microstrip lines } \\
& $\begin{array}{c}\text { Sylgard } \\
170\end{array}$ & $\begin{array}{c}\text { EG3896- } \\
\text { microspheres }\end{array}$ & $\begin{array}{c}\text { Sylgard } \\
170\end{array}$ & $\begin{array}{c}\text { EG3896- } \\
\text { microspheres }\end{array}$ \\
\hline CI-1036 & + & & + & \\
CI-1036 mod & + & + & + & + \\
CI-1075 & + & & + & + \\
CI-4040 & + & + & + & + \\
DA6534 & + & & & + \\
\hline \hline
\end{tabular}

TABLE VII shows combinations of materials in our investigation. The combinations of Sylgard 170 with different conducting layers are meant to show the effect of conductivity on the device's performance, while the combinations EG3896 with 50\% microspheres (modified gel) with the worst and the best conductivity are meant to show the effect of the dielectric loss on the device's performance.

Many materials that are used in the "flexible" electronics can be considered flexible only with extremely small thicknesses (around 100um), e.g., polyimide (Kapton) [39], polyethylene [40], PTFE [41], and others [42], [7], [43]. To show the fair flexibility our polymer-based microwave devices, the substrate thickness is $3 \mathrm{~mm}$ in all cases.

The microstrip line width $(\mathrm{Wm})$ is $8.1 \mathrm{~mm}$ for Sylgard 170 (Dk 3.1) substrate and $11.5 \mathrm{~mm}$ for the modified gel (Dk 1.85) substrate. CPW central line width (W) is $2.4 \mathrm{~mm}$ with $0.4 \mathrm{~mm}$ gap for Sylgard 170 and $3.9 \mathrm{~mm}$ with $0.5 \mathrm{~mm}$ gap for modified gel. The "metallization" thickness is from 70um to 100um and exceeds 5 skin depths in all cases. DA6534 has 350um in thickness since it does not have any shrinkage after curing.

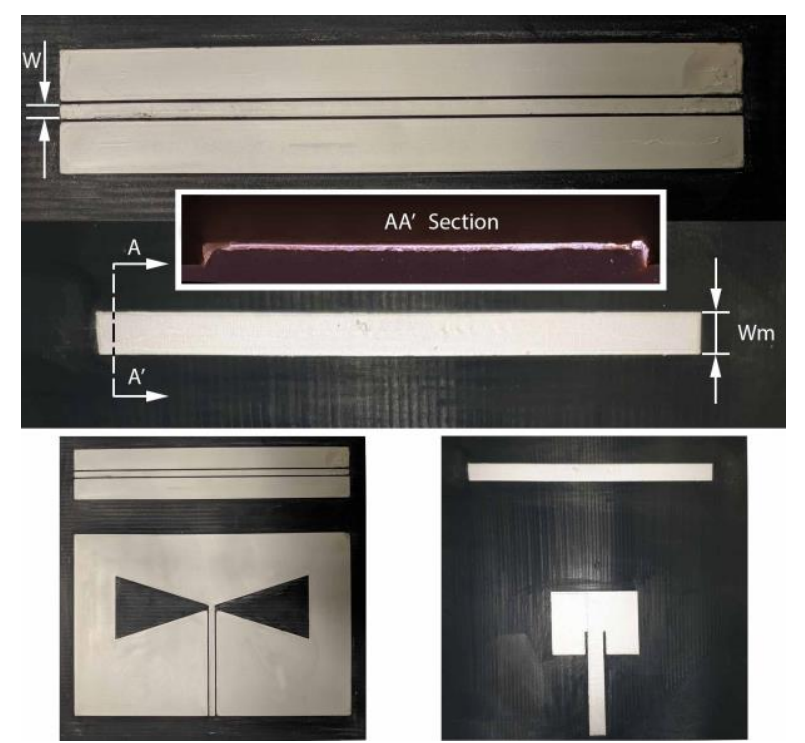

Fig. 9. Produced a) patch antenna and microstrip line, b) slotted bow-tie antenna, and CPW line.

\section{MEASUREMENTS}

S-parameters measurements have been done on R\&S ZVA50 with modified SMA end-launch connectors. Temperaturedependent measurements have also been done in the thermally-insulated chamber.

\section{A. Connectors}

The conducting polymers CI series and PE873 can be soldered to connectors with low-temperature eutectic alloys. However, the point of contact enforces additional stress in a very small area, which leads to cracks and tears. To resolve these issues, the SMA Radiall (R125.541.000) end-launch connectors have been modified in such a way that it allows connection without soldering.

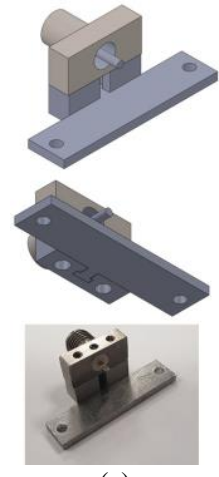

(a)

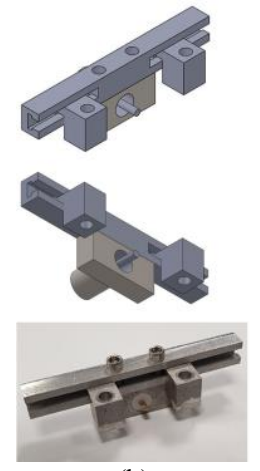

(b)
Fig. 10. Modified SMA connectors for (a) microstrip and (b) for CPW application.

Fig. 10 illustrates configurations for CPW and microstrip connection. The dark grey parts have been printed on a 3D printer from aluminum alloy. This configuration allows using connectors with very thick substrates up to $8 \mathrm{~mm}$, adjustable CPW pitch, fast and repeatable reconnection from one setup to another. The conducting silver paint has been used to fill the gaps between conducting polymers and connectors to ensure proper ohmic connection and mitigate excessive loss due to oxidation layers. 


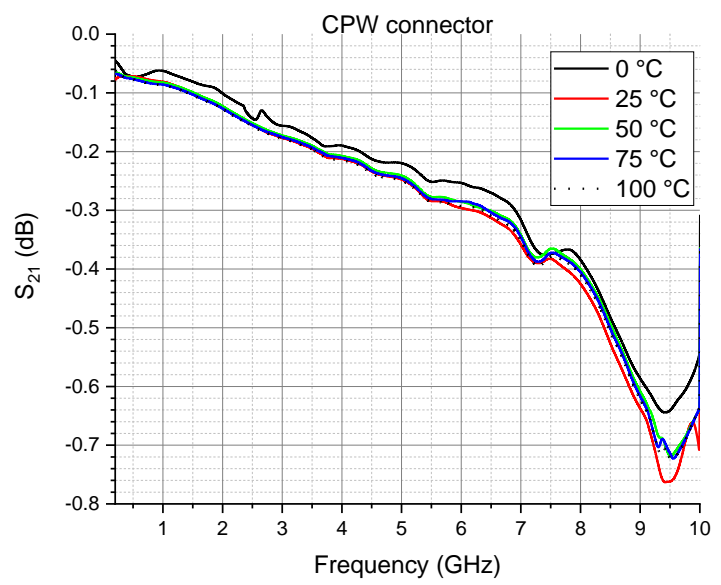

Fig. 11. $\mathrm{S}_{21}$ parameters of modified connector for CPW application versus temperature.

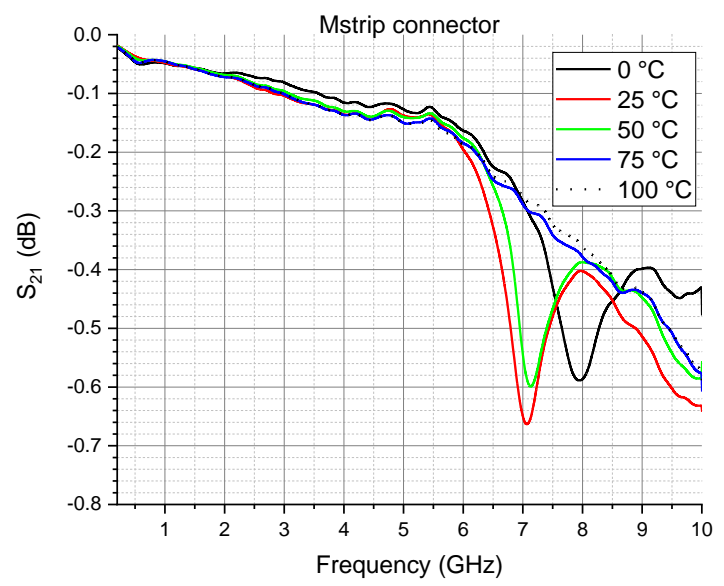

Fig. 12. $\mathrm{S}_{21}$ parameters of modified connector for microstrip application versus temperature.

To obtain accurate data for transmission lines versus temperature, we have performed deembedding [44]. The connetctor's parameters have been extracted at different temperatures. The reflection coefficients are below $-20 \mathrm{~dB}$ and fluctuate within a few $\mathrm{dB}$ vs. temperature. Transmission coefficients improve at the low temperature by $0.02 \mathrm{~dB}$ or less. This is the expected behavior of connectors since metal's conductivity increases at low temperatures, but also Teflon's and metal's thermal shrinkage and expansion slightly modify dimensions, which leads to some impedance variations. The significant degradation has been observed at the frequency band from 6 to $9 \mathrm{GHz}$ in modified connector for microstrip application and from $8 \mathrm{GHz}$ to $10 \mathrm{GHz}$ for $\mathrm{CPW}$ application. This is reflected in the device measurements, and we could not deembed such fluctuation entirely.

\section{B. Microstrip and CPW Transmission Lines}

The CPW and microstrip transmission lines with different conducting and dielectric polymers are discussed in this subsection, where the data have been measured at the room temperature and deembedded. As a result, the relation between conductivity and transmission loss is presented for further developments of flexible polymer-based microwave devices.

All the measured $S_{11}$ parameters of $\mathrm{CPW}$ and microstrip lines are below $-10 \mathrm{~dB}$ for $\mathrm{CPW}$ lines and $-15 \mathrm{~dB}$ for microstrip lines (Fig. 13), which indicates acceptable port matching. The wavy responses in $\mathrm{S}_{21}$ parameters (Fig. 14, Fig. 15) indicate that the characteristic impedance may deviate from optimum due to excessive fringing field effects, modifications in connectors, and minor dimension variations. Relatively high substrate thickness in $3 \mathrm{~mm}$ and low dielectric constant promote excessive radiation, leading to slightly high transmission loss [45]. Additionally, some energy has been absorbed in the conducting and dialectic material, causing slanted $S_{21}$. The microstrip line with DA6534 in Fig. 15 has some degradation at low frequencies, which indicates a poor ohmic connection with connectors, probably due to oxide layers. Nevertheless, most of the transmission losses for microstrip and CPW lines are below $0.1 \mathrm{~dB} / \mathrm{cm}$ at $2.5 \mathrm{GHz}$, regardless of defects, mismatch, and radiation.

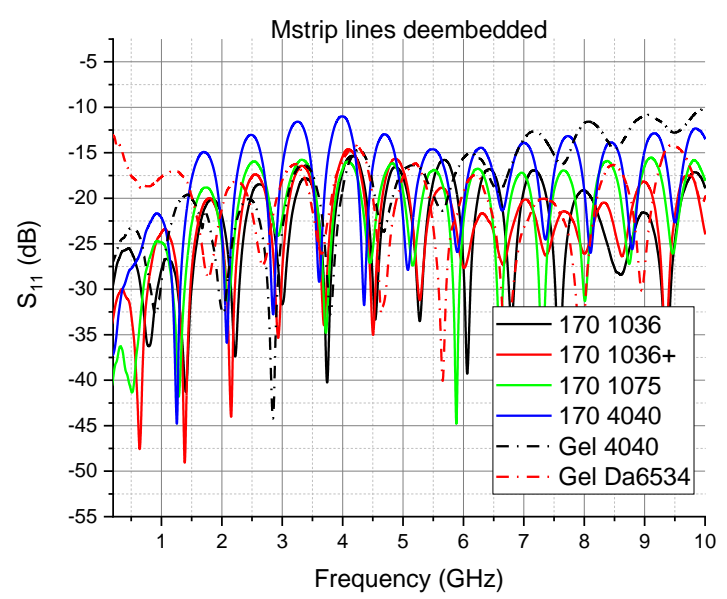

Fig. 13. $S_{11}$ parameters of microstrip lines with various conducting polymers after deembedding. 170 is Sylgard 170, Gel is EG3896 with 50\% K20 microspheres.

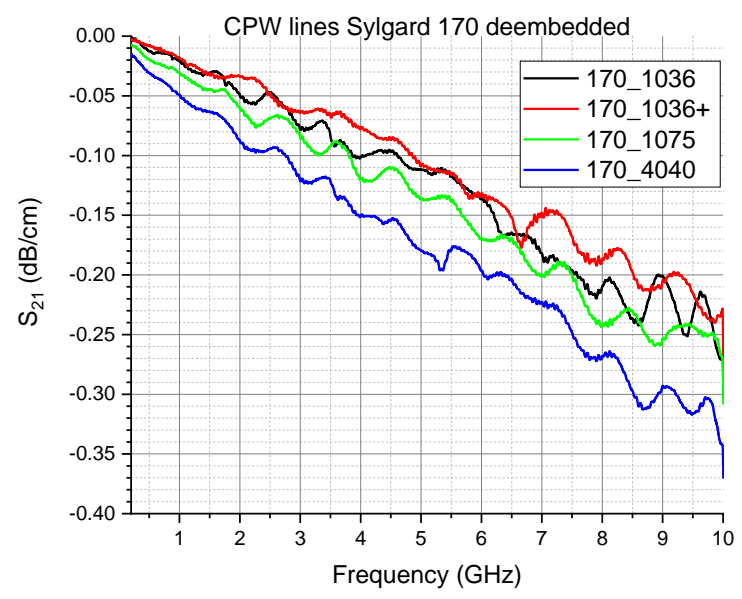

Fig. 14. Transmission loss per cm of CPW lines with Sylgard 170 PDMS (170) as the dielectric and various conducting polymers after deembedding. 
It is worth mentioning that the substrate thickness becomes comparable to $10 \%$ of the operating wavelength for microstrip and CPW lines from Sylgard 170 at $5.6 \mathrm{GHz}$ and $6.4 \mathrm{GHz}$, from modified PDMS at $6.8 \mathrm{GHz}$, and $7.8 \mathrm{GHz}$, respectively. This means that certain performance degradation is plausible beyond these frequencies due to emerging of high-order modes and random spurious responses.

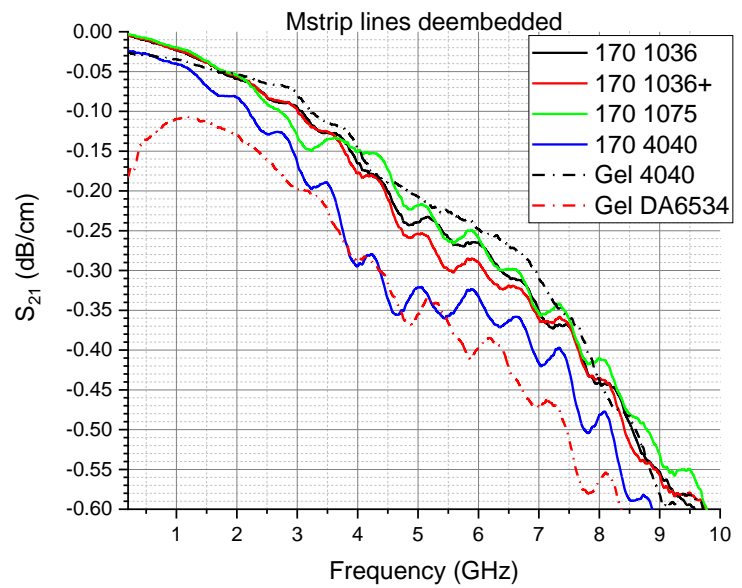

Fig. 15. Transmission loss per $\mathrm{cm}$ of microstrip lines with various conducting polymers after deembedding. 170 is Sylgard 170, Gel is EG3896 with 50\% K20 microspheres.

TABLE VIII

MEASURED TRANSMISSION LOSS OF WAVEGUIDES (DB/CM) AT $2.5 \mathrm{GHz}$

\begin{tabular}{ccccc}
\hline \hline \multirow{2}{*}{$\begin{array}{c}\text { Conducting } \\
\text { polymers }\end{array}$} & \multicolumn{2}{c}{ Microstrip } & \multicolumn{2}{c}{ CPW } \\
\cline { 2 - 5 } & Sylgard & Mod & Sylgard & Mod \\
& 170 & EG3896 & 170 & EG3896 \\
\hline CI-1036 & 0.084 & -- & 0.051 & 0.034 \\
CI-1036 mod & 0.084 & -- & 0.049 & -- \\
CI-1075 & 0.091 & -- & 0.068 & -- \\
CI-4040 & 0.129 & 0.065 & 0.094 & -- \\
DA6534 & -- & 0.162 & -- & -- \\
\hline \hline
\end{tabular}

TABLE VIII summarizes the transmission loss with various combinations of materials. The CST simulation for CPW mod EG3896 with CI-1036 shows $0.02 \mathrm{~dB} / \mathrm{cm}$, an analytical solution for quasi-TEM wave [46] gives $0.043 \mathrm{~dB} / \mathrm{cm}$, while the measured value is around $0.034 \mathrm{~dB} / \mathrm{cm}$. The current results of the new batch are consistent with our previous batch measured one year ago [16], which proves reproducibility.

Fig. 16 shows the simulated data of transmission loss in CST from Sylgard 170 and measured data of CPW and microstrip transmission lines. The measured and simulated data of the CPW lines are in very good agreement with slight fluctuation around the predicted values. The microstrip lines have higher discrepancies with simulated values. It might be due to additional fringing fields in the $\pi$-shaped strictures. A similar effect we can observe in the microstrip patch antennas in [38].

From simulated and measured data, we can see that the transmission loss for both types of lines increases drastically below conductivity in $1 \times 10^{6} \mathrm{~S} / \mathrm{m}$. This borderline could serve as an acceptable limit for the conducting polymers in the polymer-based microwave devices, which operate in $\mathrm{S}$ and $\mathrm{L}$ bands. The further improvements in conductivity have a small effect on the transmission loss and might be considered as a trade-off between conductivity and flexibility based on the application of flexible microwave electronics.

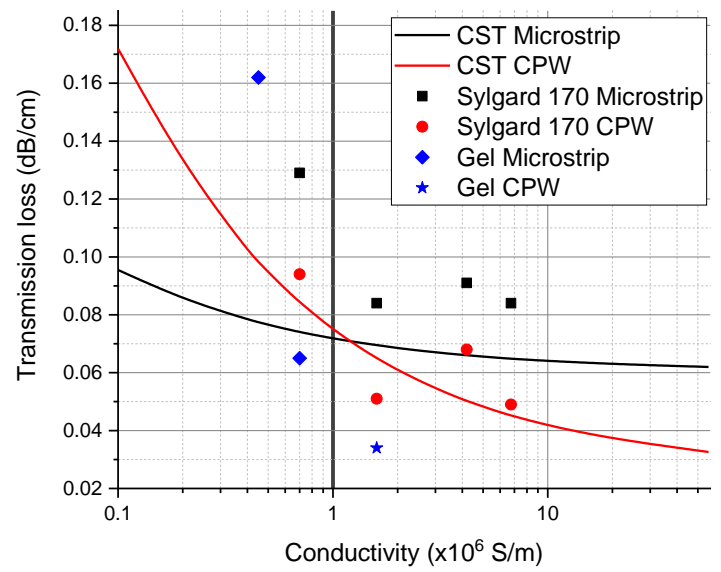

Fig. 16. Simulation and measured results of transmission loss at $2.5 \mathrm{GHz}$ versus conductivity. Gel is EG3896 with 50\% K20 microspheres.

\section{Temperature-Dependent Measurements}

The polymers have been investigated versus temperature to understand the temperature-dependent behavior of polymerbased devices. The samples have been attached to the chuck of a probe station with the capability to vary the temperature from $-60{ }^{\circ} \mathrm{C}$ to $200{ }^{\circ} \mathrm{C}$. An improvised chamber with thermal insulation has been designed and built to maintain the required temperature. Nitrogen gas has constantly been purging into the chamber to minimize frost and water condensation on the samples. The temperature has been monitored via thermocouple probes. The measurements of the conducting polymers have been performed with the 4-point probe station, and the data is summarized in TABLE IX. The aluminum foil is used as a reference due to its well-known temperaturedependent behavior.

TABLE IX

POLYMER CONDUCTIVITY VS. TEMPERATURE

\begin{tabular}{cccc}
\hline \hline \multirow{2}{*}{ Name } & \multicolumn{3}{c}{ Measured Conductivity $\left(10^{6} \mathrm{~S} / \mathrm{m}\right)$} \\
\cline { 2 - 4 } & $-30{ }^{\circ} \mathrm{C}$ & $25^{\circ} \mathrm{C}$ & $100{ }^{\circ} \mathrm{C}$ \\
\hline CI-1036 mod & 7.84 & 5.68 & 4.37 \\
CI-1075 & 9.6 & 6.58 & 5.44 \\
CI-4040 & 1.251 & 1.16 & 0.84 \\
DA6534 & $0.59-0.8$ & 0.449 & 0.59 \\
Aluminum & 45.1 & 30.4 & 22.5 \\
\hline \hline
\end{tabular}

Since the conducting polymers consist of silver particles and polymer matrix, we can expect that silver as a conducting component would behave as a normal metal, i.e., conductivity is rising at low temperatures and decreasing at high temperatures. It is well understood via phonon-electron interaction mechanisms. The polymer matrices behave very differently with the temperature variation. It depends on the polymer structure, linearity, molecular weight, cross-link structure, and density. The CI series's polymer matrices are the same, which is highly branched vinyl-chloride, vinyl-acetate maleic acid terpolymer. Based on the measured data, it seems 
that this polymer has a relatively low expansion rate vs. temperature and has little impact on the polymer-silver structure.

In contrast, we can see that conductivity rises and at low and at high temperatures compared to the room temperate, but also, we have observed that different test areas have slightly different conductivity, which points to inhomogeneity in the bulk material. The polymer DA6534 is PDMS based and exhibits relatively high expansion and shrinkage vs. temperature. This might result in some redistribution of silver particles, and hence, a different concentration in the bulk material. It deserves further discussion.

Four transmission lines have been chosen for performance evaluation versus temperature: microstrip lines made from Sylgard 170 with CI-1036 and compound EG3896 + 50\% K20 microspheres with CI-4040; CPW lines made from Sylgard 170 with CI-1036 and EG3896 + 50\% K20 microspheres with CI-1036.

The reflection coefficients (Fig. 17) have become worse at high frequencies compared to the room temperature setup Fig. 13. This is because of the existence of the heat transferring metallic plates, thermocouple attached, the thermally-insulated chamber, and other factors in the proximity of transmission lines. However, it does not jeopardize the experiment's results since we are interested in the relative values of the transmission loss at different temperature conditions.

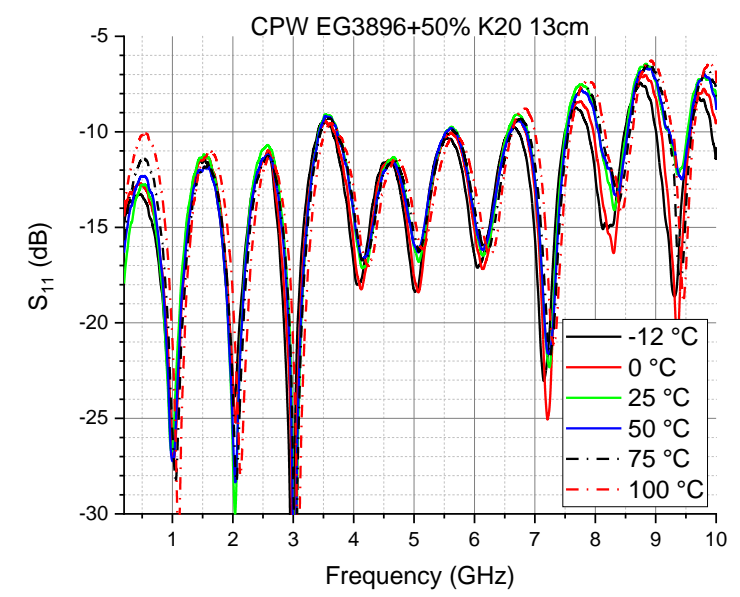

Fig. 17. $\mathrm{S}_{11}$ parameters of the $13 \mathrm{~cm}$ long CPW line made from EG3896+50\% $\mathrm{K} 20$ compound as the dielectric and CI-1036 versus temperature.

The measured data of transmission lines performance shows that the transmission loss decreases with the elevation of temperature. It can be observed $1 \mathrm{~dB}$ difference at $2.5 \mathrm{GHz}$, $1.93 \mathrm{~dB}$ at $4 \mathrm{GHz}, 3.3 \mathrm{~dB}$ at $8.5 \mathrm{GHz}$ for microstrip line in Fig. 18. The CPW line in Fig. 19 shows $0.6 \mathrm{~dB}$ difference at 2.5 $\mathrm{GHz}, 0.8 \mathrm{~dB}$ at $4 \mathrm{GHz}$, and $3.2 \mathrm{~dB}$ at $8.5 \mathrm{GHz}$. Transmission lines from EG3896 compound has 3-4 times less transmission loss variation versus temperature, as shown in Fig. 20 and Fig. 21 , which can be explained by the smaller dielectric loss in EG3896 compound (TABLE I).

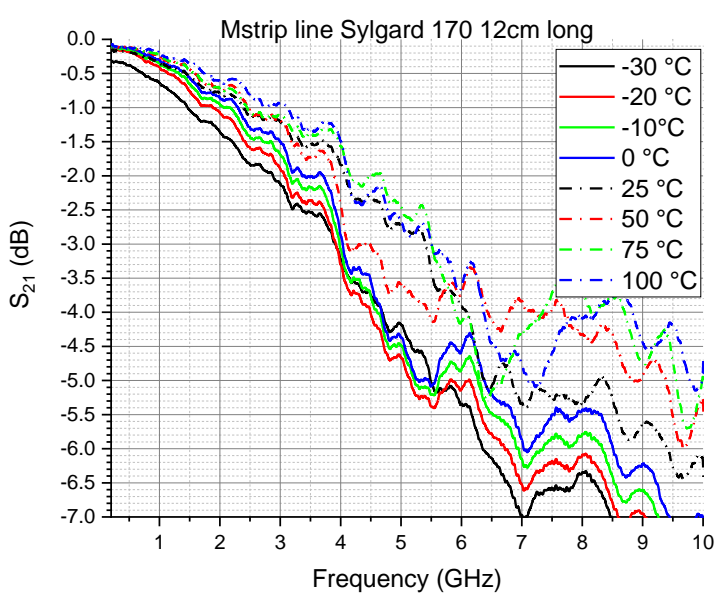

Fig. 18. $\mathrm{S}_{21}$ parameters of the $12 \mathrm{~cm}$ long microstrip line made from Sylgard 170 PDMS as the dielectric and CI-1036 versus temperature.

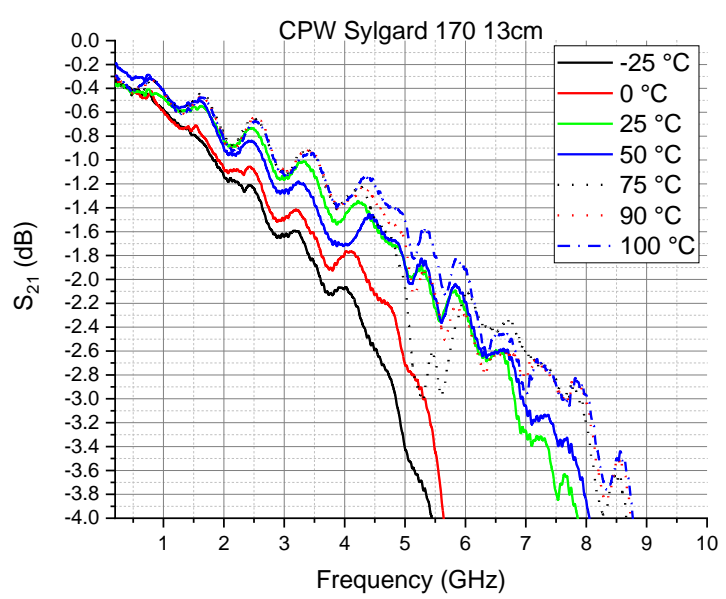

Fig. 19. $\mathrm{S}_{21}$ parameters of the $13 \mathrm{~cm}$ long CPW line made from Sylgard 170 PDMS as the dielectric and CI-1036 versus temperature.

The conductivities of connector's metal and conducting polymer decrease with temperature, which results in an excessive ohmic loss. However, this ohmic loss has been compensated by improvements in the dielectric loss of polymers. Our transmission method using waveguides can not accurately determine the dielectric constant and dielectric loss of polymers at different temperatures. One of the possible solutions is using double chamber waveguide [47]. Although we observe dielectric constant variation and thermal expansion, but these can not explain such big improvements at high temperatures. MIT report [48] indicates that some organic materials can have 2-4 times lower dielectric loss at high temperatures. A combination of organic and non-organic materials can be used for the development of thermostable microwave devices. 


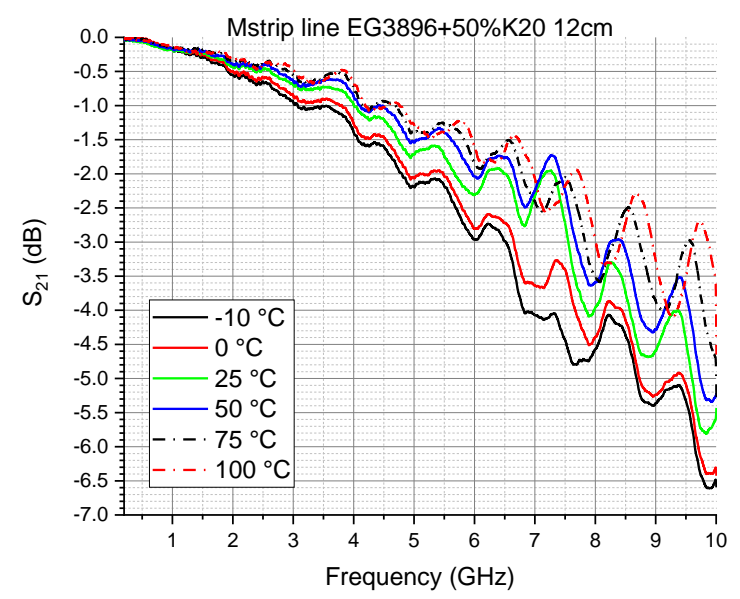

Fig. 20. $\mathrm{S}_{21}$ parameters of the $12 \mathrm{~cm}$ long microstrip line made from EG3896+50\% K20 compound as the dielectric and CI-4040 versus temperature.

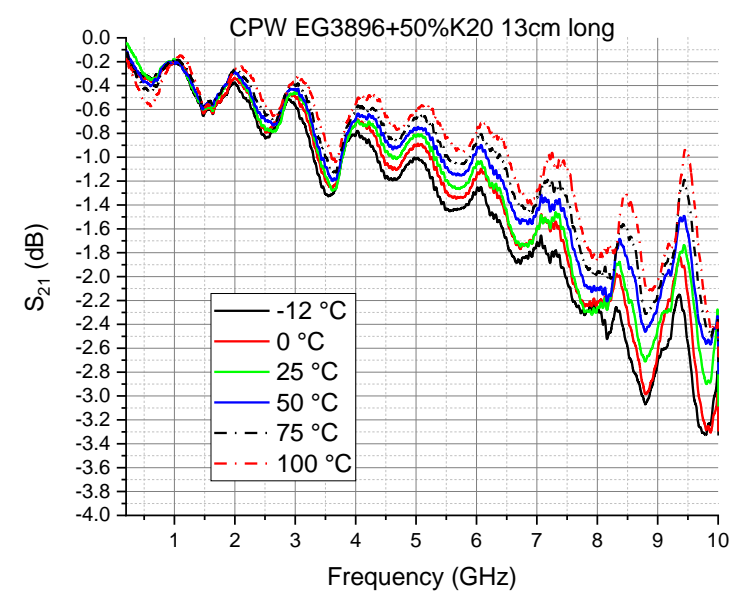

Fig. 21. $\mathrm{S}_{21}$ parameters of the $13 \mathrm{~cm}$ long CPW line made from EG3896+50\% $\mathrm{K} 20$ compound as the dielectric and CI-1036 versus temperature.

\section{Mechanical properties}

It is impossible to ignore the mechanical properties of flexible polymer-based microwave devices. The combination of dielectric and conducting polymer materials, their shapes, thicknesses, positions, and many other parameters influence the final flexibility. The bendability of CPW lines has been measured using the 3-point bending technique by placing between two support points with a $30 \mathrm{~mm}$ gap. Fig. 22 shows that it requires $1.3 \mathrm{~N}$ to bend CPW line from Sylgard 170 and CI-1036 towards metallization plane, but only $1 \mathrm{~N}$ force in the opposite direction. The EG3896 compound requires four times less force regardless of bending direction. The bending angle is $90^{\circ}$ at $10 \mathrm{~mm}$ extension. $0.3 \mathrm{~N}$ is a very small force and can be comparable to the force to bend a paper envelope. In fact, the overall bendability of polymer-based microwave devices using EG3896 compound is better than usual polymers such as Sylgard 170 or Sylgard 184.

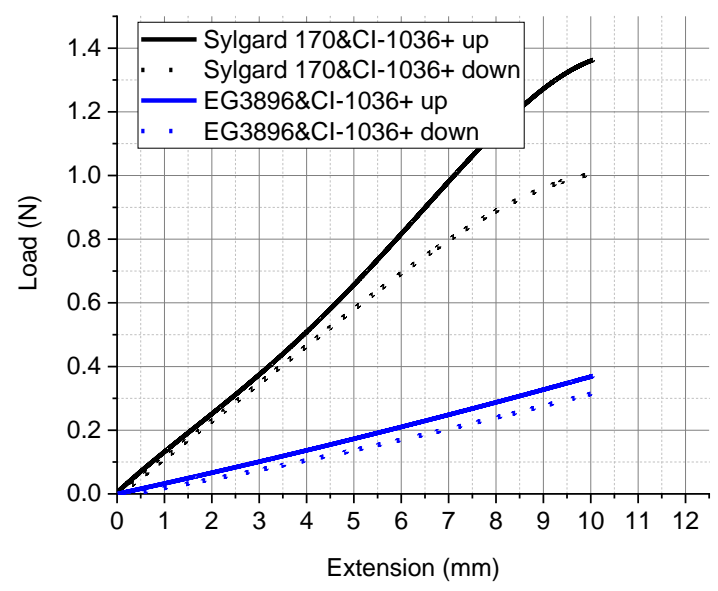

Fig. 22. 3-point bending measurement results of CPW lines made from Sylgard 170 and EG3896+50\%K20 compound [15].

\section{CONCLUSION}

In this paper, we have achieved fully flexible microwave devices. Commercially available flexible polymers have been investigated in terms of chemical, mechanical, and electrical properties. Moreover, the fabrication techniques for polymerbased microwave devices have been developed to address the chemical adhesion and demolding issues. Finally, based on formulated criteria, we have developed recipes for low-loss, low-Dk flexible dielectric materials and applied them to the microstrip and CPW transmission lines. The effects of various materials on microwave performance have been analyzed, from which we show acceptable limits for fully flexible microwave devices in $\mathrm{S}$ and $\mathrm{L}$ bands. The temperaturedependent measurements have been performed, and it has been found that the polymer-based devices have non-classical behavior and show significant performance improvements with elevated temperatures, which can be further explored and exploited in thermal-stable devices.

The proposed recipes for low-loss, low-Dk dielectric materials and chemical integration between conducting polymers and PDMS have been presented and tried on several microwave devices. The current molding process allows us to step out from 2D PCB designs and build 3D structures or hybrid PCB-3D components with a certain freedom in material properties. Additionally, the new material exhibits unique mechanical properties, i.e., low density, temperature insulation, vibration and acoustic damping effects, low humidity absorption, etc., which extends the material application to other fields.

With all these materials, production, and technological improvements, this work demonstrates that we can achieve fully flexible polymer-based microwave devices, whose performance is comparable to the state-of-the-art rigid PCB devices.

\section{ACKNOWLEDGMENT}

The authors gratefully acknowledge support from Dow 
Corning chemical department of Singapore and 3M, Nouryon companies for provided samples.

\section{REFERENCES}

[1] X. Lin, Y. Chen, Z. Gong, B. C. Seet, L. Huang, and Y. Lu, "Ultrawideband Textile Antenna for Wearable Microwave Medical Imaging Applications," IEEE Trans. Antennas Propag., vol. 68, no. 6, pp. 4238-4249, 2020.

[2] A. S. M. Alqadami, N. Nguyen-Trong, B. Mohammed, A. E. Stancombe, M. T. Heitzmann, and A. Abbosh, "Compact Unidirectional Conformal Antenna Based on Flexible High-Permittivity Custom-Made Substrate for Wearable Wideband Electromagnetic Head Imaging System," IEEE Trans. Antennas Propag., vol. 68, no. 1, pp. 183-194, 2020.

[3] A. Veeraselvam, G. N. A. Mohammed, K. Savarimuthu, M. Marimuthu, and B. Balasubramanian, "Polarization diversity enabled flexible directional UWB monopole antenna for WBAN communications," Int. J. RF Microw. Comput. Eng., vol. 30, no. 9, pp. 1-12, 2020.

[4] H. Lee, M. M. Tentzeris, and J. Geiger, "Flexible spiral antenna with microstrip tapered infinite balun for wearable applications," IEEE Antennas Propag. Soc. AP-S Int. Symp., pp. 1-2, 2012.

[5] Q. H. Abbasi, M. U. Rehman, X. Yang, A. Alomainy, K. Qaraqe, and E. Serpedin, "Ultrawideband band-notched flexible antenna for wearable applications," IEEE Antennas Wirel. Propag. Lett., vol. 12, pp. 16061609, 2013.

[6] F. Tariq, Q. Amjad, A. Kamran, A. Hassan, and R. Karim, “A flexible antenna on cost-effective PEN substrate for sub-6 GHz 5G wireless transceivers," Proc. - 2019 Int. Conf. Front. Inf. Technol. FIT 2019, pp. 89-94, 2019.

[7] Y. Zhou, S. Sivapurapu, M. Swaminathan, and S. K. Sitaraman, "Mechanical and High-Frequency Electrical Study of Printed, Flexible Antenna under Deformation," IEEE Trans. Components, Packag. Manuf. Technol., vol. 10, no. 7, pp. 1088-1100, 2020.

[8] K. K. Naik, S. C. S. Teja, B. V. S. Sailaja, and P. A. Vijaya Sri, "Design of flexible parasitic element patch antenna for biomedical application," Prog. Electromagn. Res. M, vol. 94, no. March, pp. 143-153, 2020.

[9] M. Rizwan, M. W. A. Khan, H. He, J. Virkki, L. Sydänheimo, and L. Ukkonen, "Flexible and stretchable 3D printed passive UHF RFID tag," Electron. Lett., vol. 53, no. 15, pp. 1-2, 2017.

[10] A. S. M. Alqadami, M. F. Jamlos, P. J. Soh, and G. A. E. Vandenbosch, "Assessment of PDMS Technology in a MIMO Antenna Array," IEEE Antennas Wirel. Propag. Lett., vol. 15, pp. 1939-1942, 2016.

[11] D. P. Wang, Z. H. Zhao, C. H. Li, and J. L. Zuo, "An ultrafast selfhealing polydimethylsiloxane elastomer with persistent sealing performance," Mater. Chem. Front., vol. 3, no. 7, pp. 1411-1421, 2019.

[12] S. H. Cho, S. R. White, and P. V. Braun, "Room-temperature polydimethylsiloxane-based self-healing polymers," Chem. Mater., vol. 24, no. 21, pp. 4209-4214, 2012.

[13] M. Wehner et al., "An integrated design and fabrication strategy for entirely soft, autonomous robots," Nature, vol. 536, no. 7617, pp. 451455, 2016.

[14] Y. Bar-cohen, "Electroactive polymer (EAP) actuators — background review," Mech. Soft Mater., vol. 1:5, pp. 1-14, 2019.

[15] I. Cherukhin and G. Y. Xin, "Performance improvements in flexible polymer-based microwave devices," Asia-Pacific Microw. Conf. Proceedings, APMC, vol. 2019, pp. 619-621, 2019.

[16] I. Cherukhin, F. V. Zander, A. K. Dashkova, and Y. X. Guo, "Investigation of material properties for polymer-based microwave devices," J. Phys. Conf. Ser., vol. 1399, no. 4, 2019.

[17] M. P. Wolf, G. B. Salieb-Beugelaar, and P. Hunziker, "PDMS with designer functionalities-Properties, modifications strategies, and applications," Prog. Polym. Sci., vol. 83, pp. 97-134, 2018.

[18] J. N. Lee, C. Park, and G. M. Whitesides, "Solvent compatibility of poly(dimethylsiloxane)-based microfluidic devices," Anal. Chem., vol. 75, no. 23, pp. 6544-6554, 2003.

[19] L. K. Namitha, J. Chameswary, S. Ananthakumar, and M. T. Sebastian, "Effect of micro- and nano-fillers on the properties of silicone rubberalumina flexible microwave substrate," Ceram. Int., vol. 39, no. 6, pp. 7077-7087, 2013.

[20] M. T. Nazir, B. T. Phung, M. Hoffman, S. Yu, and S. Li, "MicroAlN/nano-SiO2 co-filled silicone rubber composites with high thermal stability and excellent dielectric properties," Mater. Lett., vol. 209, pp.
421-424, 2017.

[21] L. K. Namitha and M. T. Sebastian, "High permittivity ceramics loaded silicone elastomer composites for flexible electronics applications," Ceram. Int., vol. 43, no. 3, pp. 2994-3003, 2017.

[22] F. Madidi, G. Momen, and M. Farzaneh, "Dielectric Properties of TiO2/Silicone Rubber Micro- and Nanocomposites," Adv. Appl. Polym. Nanocomposites, vol. 2018, pp. 1-7, 2018.

[23] G. Ouyang, K. Wang, and X. Y. Chen, "TiO2 nanoparticles modified polydimethylsiloxane with fast response time and increased dielectric constant," J. Micromechanics Microengineering, vol. 22, no. 7, pp. 1-9, 2012.

[24] A. Bele, M. Cazacu, G. Stiubianu, S. Vlad, and M. Ignat, "Polydimethylsiloxane-barium titanate composites: Preparation and evaluation of the morphology, moisture, thermal, mechanical and dielectric behavior," Compos. Part B, vol. 68, pp. 237-245, 2015.

[25] L. K. Namitha and M. T. Sebastian, "Microwave dielectric properties of flexible silicone rubber - $\mathrm{Ba}(\mathrm{Zn} / \mathrm{Ta}) \mathrm{O}$ composite substrates," Mater. Res. Bull., vol. 48, no. 11, pp. 4911-4916, 2013.

[26] M. T. Sebastian and H. Jantunen, "Polymer-ceramic composites of 0-3 connectivity for circuits in electronics: A review," Int. J. Appl. Ceram. Technol., vol. 7, no. 4, pp. 415-434, 2010.

[27] P. G. Shakhil et al., "Preparation, characterization and dielectric properties of $\mathrm{Ca} 2 \mathrm{ZrSi} 4 \mathrm{O} 12$ ceramic and filled silicone rubber composites for microwave circuit applications," Mater. Sci. Eng. B, vol. 225, no. May, pp. 115-121, 2017.

[28] M. T. Sebastian, Dielectric Materials for Wireless Communications. Elsevier, 2008.

[29] M. T. Sebastian, Microwave Materials and Applications. Wiley-VCH, 2017

[30] M. T. Sebastian, R. Ubic, and H. Jantunen, Microwave Materials and Applications. Wiley-VCH, 2017.

[31] P. Gonon, T. P. Hong, O. Lesaint, S. Bourdelais, and H. Debruyne, "Influence of high levels of water absorption on the resistivity and dielectric permittivity of epoxy composites," Polym. Test., vol. 24, no. 6, pp. 799-804, 2005.

[32] T. Laverghetta, Microwave Materials and Fabrication Techniques, Third. Boston, London: Artech House, 2010.

[33] J. Chameswary and M. T. Sebastian, "Development of butyl rubberrutile composites for flexible microwave substrate applications," Ceram. Int., vol. 40, no. 5, pp. 7439-7448, 2014.

[34] J. Chameswary and M. Thomas, "Butyl rubber-Ba0.7Sr0.3TiO3 composites for flexible microwave electronic applications," Ceram. Int., vol. 39, no. 3, pp. 2795-2802, 2013.

[35] A. Larmagnac, S. Eggenberger, H. Janossy, and J. Vörös, "Stretchable electronics based on Ag-PDMS composites," Sci. Rep., vol. 4, pp. 1-7, 2014.

[36] M. Park, J. Park, and U. Jeong, "Design of conductive composite elastomers for stretchable electronics," Nano Today, vol. 9, no. 2, pp. 244-260, 2014.

[37] "SYL-OFF ${ }^{\mathrm{TM}}$ SB-7558 Coating | Dow Inc." [Online]. Available: https://www.dow.com/en-us/pdp.syl-off-sb-7558coating.04094785h.html. [Accessed: 24-Nov-2020].

[38] I. Cherukhin, S. Gao, and Y. X. Guo, "Fully Flexible, Polymer-based Microwave Devices Part II: Flexible Antennas and Performance Evaluation."

[39] S. Ahmed, F. A. Tahir, A. Shamim, and H. M. Cheema, "A Compact Kapton-Based Inkjet-Printed Multiband Antenna for Flexible Wireless Devices," IEEE Antennas Wirel. Propag. Lett., vol. 14, pp. 1802-1805, 2015.

[40] M. A. Riheen, T. T. Nguyen, T. K. Saha, T. Karacolak, and P. K. Sekhar, "CPW fed wideband bowtie slot antenna on pet substrate," Prog. Electromagn. Res. C, vol. 101, no. March, pp. 147-158, 2020.

[41] H. Liu, S. Member, S. Zhu, P. Wen, X. Xiao, and W. Che, "Flexible CPW-Fed Fishtail-Shaped Antenna for Dual-Band Applications," IEEE Antennas Wirel. Propag. Lett., vol. 13, pp. 770-773, 2014.

[42] A. C. Durgun, S. Member, C. A. Balanis, L. Fellow, C. R. Birtcher, and D. R. Allee, "Design, Simulation, Fabrication and Testing of Flexible Bow-Tie Antennas," IEEE Trans. Antennas Propag., vol. 59, no. 12, pp. 4425-4435, 2011

[43] A. Arayeshnia, A. Madannejad, J. Ebrahimizadeh, F. Ravanbakhsh, M. D. Perez, and R. Augustine, "Miniaturized CPW-fed bowtie slot antenna for wearable biomedical applications," 14th Eur. Conf. Antennas Propagation, EuCAP 2020, pp. 5-8, 2020.

[44] S.-P. Gao and I. Cherukhin, "Characterizing Microwave Connectors over Temperatures Using Thermal-stable Standards," IEEE MTT-S Int. 
Microw. Work. Ser. Adv. Mater. Process. RF THz Appl., pp. 1-3, 2020.

[45] S. L. Van Berkel, A. Garufo, N. Llombart, and A. Neto, "A QuasiAnalytical Tool for the Characterization of Transmission Lines at High Frequencies," IEEE Antennas Propag. Mag., vol. 58, no. 3, pp. 82-90, 2016.

[46] D. M. Pozar, Microwave Engineering. 1997.

[47] A. E. Bogle, M. W. Hyde, M. J. Havrilla, and J. S. Sovern, "Hightemperature RF material characterization using a dual-chambered rectangular waveguide fixture," IEEE Trans. Instrum. Meas., vol. 66, no. 9, pp. 2422-2427, 2017.

[48] W. B. Westphal and A. Sils, Dielectric constant and Loss Data. Technical Report AFML-TR-72-39. USA: Air force material laboratory, 1972. 